\title{
ARACNÍDEOS NO ENSINO DE CIÊNCIAS BIOLÓGICAS: UMA ANÁLISE DOS ARTIGOS PUBLICADOS
}

\author{
Lucas Carvalho Sandonato Silva1, Wesley Dondoni Colombo ${ }^{2}$ \\ Isabel De Conte Carvalho de Alencar ${ }^{3}$ * \\ Instituto Federal do Espírito Santo - Campus Santa Teresa \\ Coordenadoria do Curso de Licenciatura em Ciências Biológicas \\ Rodovia ES-080, km 93. São João de Petrópolis \\ Santa Teresa - Espirito Santo Tel. (27) 3259-7878
}

\begin{abstract}
RESUMO
Ensinar Ciências implica estabelecer pontes entre o conhecimento que os cientistas expressam e o conhecimento que os alunos deverão construir. A Classe Arachnida foi escolhida por ser representada, principalmente, pelas aranhas e escorpiões, animais estes, de grande interesse médico. Raros são os trabalhos que buscam evidenciar e abordar as múltiplas visões que abarcam os ditos "animais peçonhentos", neste caso, os aracnídeos, com enfoque aos entendimentos funcionalistas, imediatistas e utilitaristas preponderantes, a fim de discutir como estas diferentes abordagens podem ser trabalhadas em sala de aula como uma proposta de ensino que venha romper com os conceitos equivocados e (pré) conceitos reproduzidos em livros didáticos, enciclopédias, na mídia, etc. Foi identificado, um artigo que trata da relação de aracnídeos e o Ensino de Ciências, mostrando que não existe uma linha cronológica de estudos sobre esse tema, indicando que são precários.
\end{abstract}

Palavras-chave: aracnologia; educação em ciências; ensino de biologia; etnobiologia.

\begin{abstract}
Teaching science involves building bridges between the knowledge that scientists express and knowledge that students should build. The Class Arachnida was chosen because it represented mainly by the spiders and scorpions, these animals, of great medical interest. Few studies that seek to highlight and address the multiple views that span the so-called "venomous animals" in this case, arachnids, with functionalist approach to understanding, immediacy and utilitarian prevalent in order to discuss how these different approaches can be worked in classroom as a teaching that will break the misconceptions and (pre) concepts reproduced in textbooks, encyclopedias, media, etc. Been identified, an article that deals with the relationship of arachnids and Science Teaching, showing that there is a timeline of studies on this subject.
\end{abstract}

Keywords: arachnology; science education; biology teaching; ethnobiology.

\footnotetext{
1 Aluno de IC do Técnico em Meio Ambiente. Ifes - Campus Santa Teresa. Email: lucas_sandonato@hotmail.com

2 Aluno de IC do curso de Licenciatura em Ciências Biológicas, Ifes - Campus Santa Teresa. E-mail: wesleycolombo@gmail.com

3 Professora de Ciências Biológicas, M.Sc. - Coordenadoria do Curso de Licenciatura em Ciências Biológicas. Ifes - Campus Santa Teresa. E-mail: idccalencar@gmail.com
} 


\section{INTRODUÇÃO}

As disciplinas de Ciências, para o Ensino Fundamental e de Ciências Biológicas, para o Ensino Médio estão em constante atualização dos conhecimentos gerados (LOMBARDI e FERREIRA, 2010), por isso, análises na produção acadêmica são importantes para mapear o nível atual das pesquisas na área e ainda, possibilitar que futuros estudos sejam realizados. 0 Ensino de Ciências deve partir do conhecimento cotidiano, e vivenciando este cotidiano, o aluno sente-se motivado a aprender o conteúdo científico, porque faz parte da cultura, do desenvolvimento tecnológico e no modo de pensar de todos (DELIZOICOV e ANGOTTI, 1994; BRASIL, 1997) e assim criar pontes entre o conhecimento e o conhecimento adquirido pelos alunos em sala de aula (SANMARTI, 2002). Ligações antigas entre animais e seres humanos são vistas em culturas de todo o mundo e de múltiplas formas de interação com a fauna local que formam o núcleo da Etnozoologia (ALVES e SOUTO, 2011), e quando tratamos dos aracnídeos, passamos a chamar este núcleo de interações de Etnoaracnologia.

Os aracnídeos são invertebrados da Classe Arachnida, composta predominantemente por animais terrestres (DUNLOP e WEBSTER, 1999). Estão incluídas nesta Classe as formas mais comuns e familiares de animais, como aranhas, escorpiões, ácaros e carrapatos (WALTER e PROCTOR, 1999). O ser humano possui uma tendência inata de concentrar sua atenção à vida e os processos vitais (WILSON, 1989), o que se confirma durante os primeiros estágios do desenvolvimento cultural, pois o estudo da natureza tinha uma profunda influência na evolução da arte, das magias e religião, passando assim, a fazer parte das tradições populares (BRISTOWE, 1945; NOMURA, 2001). Segundo KELLERT (1993), as aranhas e os escorpiões se destacam por possuírem uma má fama para com o homem, uma vez que, por serem considerados frequentemente como animais que são perigosos e que causam aversão, devem ser evitados. Entretanto, existem muitas informações relevantes sobre este grupo, como por exemplo, que os escorpiões estão entre os primeiros animais a invadirem o ambiente terrestre (DUNLOP e WEBSTER, 1999); as "estratégias reprodutivas", como a partenogênese, encontrada no escorpião amarelo Tityus serrulatus (SOUZA et al., 2007); que faz com que os aracnídeos devam estar presentes no Ensino de Ciências. 
Visando o Ensino de Ciências e Biologia de qualidade nas escolas, o objetivo deste trabalho é analisar a trajetória da implantação dos aracnídeos dentro do Ensino Fundamental e Médio. Os dados gerados irão nortear futuros trabalho do Laboratório de Ensino de Biologia e Pesquisa de Invertebrados (LEPI).

\section{PROCEDIMENTOS METODOLÓGICOS}

Realizou-se um levantamento de artigos publicados, em todos os anos disponíveis pelo Portal Periódicos da CAPES relacionados à abordagem dos aracnídeos no Ensino de Ciências. Foram considerados todos os resultados ligados exclusivamente ao tema de aracnídeos no ensino, sem distinção da Área de Conhecimento, autor e/ou palavras-chave. Os artigos analisados forneceram um levantamento de dados para este trabalho com os seguintes critérios: ano de publicação, nível de formação dos autores e instituições às quais os autores dos trabalhos estão vinculados. Todos os dados foram organizados em planilhas e tabelas (TABELA 1), com o objetivo de facilitar a análise das principais tendências nos trabalhos selecionados.

TABELA 1. Dados analisados nos artigos publicados.

\begin{tabular}{c|c|c|c|c|c}
\hline $\begin{array}{c}\text { Título do } \\
\text { Artigo }\end{array}$ & $\begin{array}{c}\text { Ano de } \\
\text { Publicação }\end{array}$ & $\begin{array}{c}\text { Nome dos } \\
\text { Autores }\end{array}$ & $\begin{array}{c}\text { Nível de } \\
\text { Formação } \\
\text { dos Autores }\end{array}$ & $\begin{array}{c}\text { Instituições } \\
\text { de vínculo } \\
\text { dos autores }\end{array}$ & UF \\
\hline & & & & & \\
\hline & & & & & \\
\hline
\end{tabular}

\section{RESULTADOS E DISCUSSÃO}

Usando exclusivamente o tema de aracnídeos no Ensino de Ciências e Biologia, foi obtido apenas um artigo (TABELA 2) no Portal Periódicos CAPES durante todos os anos disponibilizados para a pesquisa na CAPES. De acordo com o artigo analisado, o período destinado nas aulas de Ciências para o ensino dos aracnídeos e a informação sobre os riscos dos animais peçonhentos, neste caso, aracnídeos, é levado aos alunos por meio de livros didáticos, porém, as escolas não adotam necessariamente o mesmo livro didático, já que esta é uma escolha de cada escola junto a seus professores. 
TABELA 2. Artigos publicados e analisados.

\begin{tabular}{|c|c|c|c|c|c|c|}
\hline $\begin{array}{c}\text { Título do } \\
\text { Artigo }\end{array}$ & $\begin{array}{c}\text { Ano de } \\
\text { Publicação }\end{array}$ & $\begin{array}{c}\text { Nome dos } \\
\text { Autores }\end{array}$ & $\begin{array}{c}\text { Nível de } \\
\text { Formação } \\
\text { dos } \\
\text { Autores }\end{array}$ & $\begin{array}{l}\text { Instituições } \\
\text { de vínculo } \\
\text { dos autores }\end{array}$ & UF & $\begin{array}{l}\text { Palavras- } \\
\text { Chave }\end{array}$ \\
\hline \multirow{2}{*}{$\begin{array}{l}\text { Aracnídeos } \\
\text { Peçonhentos: } \\
\text { Análise das } \\
\text { Informações } \\
\text { nos Livros } \\
\text { Didáticos de } \\
\text { Ciências }\end{array}$} & \multirow[t]{2}{*}{2008} & $\begin{array}{c}\text { Adriano de } \\
\text { Melo } \\
\text { Ferreira }\end{array}$ & $\begin{array}{c}\text { Mestre em } \\
\text { Biologia }\end{array}$ & $\begin{array}{l}\text { Universidade } \\
\text { Estadual de } \\
\text { Goiás e da } \\
\text { Universidade } \\
\text { Católica de } \\
\text { Goiás }\end{array}$ & GO & \multirow{2}{*}{$\begin{array}{c}\text { Aracnídeos } \\
\text { peçonhentos; } \\
\text { Ensino de } \\
\text { Ciências e } \\
\text { livros } \\
\text { didáticos. }\end{array}$} \\
\hline & & $\begin{array}{c}\text { Cynthia } \\
\text { Aparecida } \\
\text { Arossa } \\
\text { Alves } \\
\text { Soares } \\
\end{array}$ & $\begin{array}{c}\text { Mestre em } \\
\text { Biologia }\end{array}$ & $\begin{array}{l}\text { Universidade } \\
\text { Estadual de } \\
\text { Goiás }\end{array}$ & GO & \\
\hline
\end{tabular}

Segundo Ferreira e Soares (2008) a pesquisa foi além e decidiu buscar livros que são utilizados em salas de aula e compará-los entre si, sendo o resultado bem expressivo, mostrando aos pesquisadores que cada livro contém questionamentos completamente diferentes uns dos outros, geralmente abordando o mesmo tema "aracnídeos peçonhentos", mas, com abordagens e exemplos diferentes. É importante destacar que os livros didáticos trazem sempre pouca ênfase ao assunto, com títulos e questionamentos que não interagem positivamente com o aluno, ou seja, não dinamizam e atraem o aluno, gerando uma falta de interesse do aluno. Outro aspecto evidenciado foram os erros contidos nos livros que são frequentemente encontrados e podem ser considerados grotescos, podendo até mesmo prejudicar o aluno no seu processo de Ensino e Aprendizagem, como por exemplo, ilustrações trocadas de animais, em que as características obviamente não têm nada haver com as aranha ilustrada.

Segundo SOUZA et al. (2007), as diferentes interpretações que alunos, professores e demais membros da comunidade possuem a respeito de animais, revelando a existência de um desconhecimento ou conhecimento equivocado sobre os aspectos biológicos, ecológicos e comportamentais destes animais. Ressaltando que as aranhas e escorpiões somam atualmente, mais de 35 mil espécies viventes (BRUSCA e BRUSCA, 2007). Entretanto, segundo Werthein e Cunha (2009), o maior problema enfrentado por pesquisadores do Ensino de Ciências é a tradução de fenômenos em uma linguagem acessível aos alunos do 
Ensino Fundamental e Médio, acrescentando que o conteúdo para esses níveis de ensino não diz respeito aos desejos dos professores e à facilidade de entendimento pelos alunos, mas deve estar relacionado com os anseios da sociedade de passar às novas gerações as conquistas feitas pela humanidade. Resumindo, os resultados desta pesquisa nos mostram como o assunto sobre os aracnídeos e, principalmente, sobre os peçonhentos, são precários em nossa educação. Estes aracnídeos estão presentes em nosso dia-a-dia e devem ter uma atenção especial pela sociedade, pois os mesmos oferecem riscos à população e até mesmo à própria economia do país (BORGES et al.,2003).

Os métodos de ensino devem ser levados aos alunos com maior criatividade, cativação, ou seja, maior interação entre professores e alunos. Entretanto, todos os métodos e conteúdos referentes aos aracnídeos estão sendo levados para os alunos de uma forma precária, evidenciando a necessidade de uma reforma na educação voltada para esta abordagem. Segundo Werthein e Cunha (2009) para que os alunos aprendam habilidades e competências de uma enculturação científica por meio de um conteúdo atual que os ajudem a entender o mundo em que vivem, muitos trabalhos de pesquisa em Ensino de Ciências precisam ser realizados. Outra maneira, segundo Werthein e Cunha (2009) é o desenvolvimento de muitas atividades de ensino que devem ser testadas em sala de aula e também muitos cursos de formação continuada devem ser oferecidos aos professores interessados. Pois com o professorado despreparado e desprovido de instrumentação que lhe possibilite novas oportunidades de propiciar aos alunos mais abstração e memorização, as noções que os alunos adquirem se transformam em algo inútil, desestimulante e contraproducente (WERTHEIN e CUNHA, 2009).

\section{CONSIDERAÇÕES FINAIS}

Devemos ressaltar que os aracnídeos, muitas vezes estão relacionados com acidentes, assim como os escorpiões e as aranhas, por exemplo. Além das condições precárias de habitação, existe outro fator responsável por esses índices, que é a falta de conhecimento da população geral sobre a biologia desses animais peçonhentos, bem como sobre a prevenção de acidentes (FERREIRA e SOARES, 2008). Normalmente, estas informações são abordadas durante aulas das disciplinas de Ciências para o Ensino Fundamental e Biologia para o Ensino Médio. Porém, devido a alguns fatores, como a precariedade de recursos 
didáticos e a deficiência na formação dos professores, o mais utilizado dos recursos continua sendo o livro didático (FERREIRA e SOARES, 2008), do qual, "devido ao baixo poder aquisitivo da população e à elevada taxa de evasão escolar, talvez represente o único texto com que muitos brasileiros interagem durante suas vidas" (FRACALANZA, 1986, p. 28). Por isso, é importante que novas pesquisas sejam realizadas na área, para que assim, o Ensino de Ciências e de Biologia se torne cada vez mais qualificado e atualizado.

\section{AGRADECIMENTOS}

Os autores agradecem à FAPES pelo financiamento PIC-Jr PROCESSO \#57225036/2012.

\section{REFERÊNCIAS}

ALVES, R. R. N.; SOUTO, W. M. S. Ethnozoology in Brazil: current status and perspectives. Journal of Ethnobiology and Ethnomedicine. 7:22, 2011.

BORGES, R. C.; OLIVEIRA, A.; COSTA, R. M. C. Serpentes peçonhentas: identificação e procedimentos em acidentes - uma análise dos livros didáticos do Ensino Fundamental e Médio. Revista de Estudo e Pesquisa em Educação, v. 5, n. 1, p. 121-133, 2003.

BRASIL. Parâmetros Curriculares Nacionais: Ciências Naturais. Secretaria de Educação Fundamental: - Brasília, 1997.

BRISTOWE, W. S. Spider superstitions and folklore. Transactions of The Connecticut Academy of Arts and Sciences. 36: 53-90. 1945.

BRUSCA, R. C.; BRUSCA, G. J. Invertebrados. 2. ed. Rio de Janeiro: Guanabara Koogan, 2007. DELIZICOV, D.; ANGOTTI, J. A. Metodologia do Ensino de Ciências. São Paulo: Cortez, 1994. DUNLOP, J. A.; WEBSTER, M. Fossil evidence, terrestrialization and arachnid phylogeny. The Journal of Arachnology. 27:86-93. 1999.

FERREIRA, A. M.; SOARES, C. A. A. A. Aracnídeos Peçonhentos: Análise das Informações nos Livros Didáticos de Ciências. Ciências e Educação. Volume 14, n.2, p. 307-314. 2008.

FRACALANZA, H.; AMARAL, I. A.; GOUVEIA, M. S. F. O ensino de Ciências no $1^{\circ}$ grau. São Paulo: Atual Editora, 1986.

KELLERT, S. R. Values and perceptions of invertebrates. Conservation Biology. 7(4): 845855. 1993. 
LOMBARDI, F. R.; FERREIRA, A. P. N. Aprendendo sobre os Artrópodes de Forma Lúdica. REUNI - Revista Unijales. 4ª Edição, n. 4. 2010.

NOMURA, H. Os animais no folclore: aracnídeos e miriápodos. Piracicaba: Fundação Guimarães Duque/ Coleção Mossorense, v. 1237, 50p. 2001.

SANMARTÍ, N. Didáctica de las ciências en la educación secundaria obligatoria. Madrid: Editorial Síntesis. 2002.

SOUZA, C. E. P. de; SPIER, E.; SOUZA, J. G. de. O. Temática: (Re) Conhecendo os Aracnídeos Peçonhentos: Diferentes Abordagens para o Ensino de Ciências. 2007.

WALTER, D. E.; PROCTOR, H. C. Mites: ecology, evolucion and behavior. Sydney: UNSW Press, 322p. 1999.

WERTHEIN, J.; CUNHA, C. Ensino de Ciências e Desenvolvimento: O que Pensam os Cientistas. São Paulo. UNESCO, 2ª Edição. 2009.

WILSON, E. O. Biofilia. México, D. F.: Fondo de Cultura Económica. 283p. 1989. 